\title{
ABDOMINAL VERSUS VAGINAL HYSTERECTOMY;
} AN AUDIT

\author{
${ }^{*}$ DR. MUHAMMAD IKRAM, FCPS \\ Lahore
}

DR. ZOONA SAEED, MBBS

Lahore

\author{
DR. ROOHI SAEED, FRCOG \\ Lahore
}
Prof. Muhammad Saeed, FRCOG
Lahore

\begin{tabular}{ll}
\hline Article received on: & $20 / 08 / 2007$ \\
\hline Accepted for publication: & $16 / 08 / 2008$ \\
\hline
\end{tabular}

\begin{abstract}
Objective: To evaluate abdominal versus vaginal hysterectomy in relation to operative and post operative complications. Design: Single centre cross sectional study. Place and duration: The Department of Obstetric and Gynaecology, Shaikh Zayed post graduate Medical institute and Hospital, Lahore from $1^{\text {st }}$ November 2005 to $31^{\text {st }}$ October 2006 . Subject and methods: All the patients with benign indications for hysterectomy (abdominal and vaginal) were included except patients with serious / complicated medical disease. Relative informations were filled in a Performa and informations were taken from case records. Results: This audit report included 200 women. $23.3 \%$ patients of vaginal hysterectomy were in the age group of 40-45 years while 35.7\% patients of abdominal hysterectomy were in the age of $51-55$ years. Main indication for abdominal hysterectomy (85.5\%) was fibroid uterus while for vaginal hysterectomy (66.6\%) was Uterovaginal prolapse. Most common immediate post operative complication in abdominal and vaginal hysterectomy was fever in $42.8 \%$ and $20.0 \%$ respectively. Intraoperative visceral injuries were done in 4 patients in abdominal hysterectomy while no injury was done in vaginal hysterectomy. $44(80 \%)$ patients of vaginal hysterectomy were discharged with in 7 days of hospitalization while 64 (44\%) patients of abdominal hysterectomy were discharged with in 7 days of hospitalization. Conclusion: Hysterectomy either abdominal or vaginal is very safe and there were no lethal complication except few minor complications and also there was no mortality.
\end{abstract}

Key word: $\quad$ Hysterectomy, Uterovaginal Prolapse, Fever.

\section{INTRODUCTION}

Hysterectomy is a very common elective procedure in the world. There are no national data base records for this procedure in Pakistan and therefore prevalence of hysterectomy cannot be quoted. Approximately 600000 hysterectomies are performed in the United States each year $^{1}$ and $20 \%$ of women in United Kingdom undergo hysterectomy before the age of sixty (Royal College of Obstetrics \& Gynaecology) ${ }^{2}$.
Bashir $\mathrm{R}$ et $\mathrm{al}^{3}$ in an audit of complications of hysterectomy has discussed the result of 316 women. Major indications for hysterectomies in women were dysfunctional uterine bleeding, fibroid uterus, followed by prolapse. It was found that frequency of complications in fibroid was higher than that for dysfunctional uterine bleeding.

Dicter R C et al ${ }^{4}$ narrated complications of abdominal 
and vaginal hysterectomy among women of reproductive age who underwent vaginal hysterectomy experienced significantly fewer complications then women who had abdominal hysterectomy. Vaginal hysterectomy was associated with less febrile morbidity, less bleeding hence reduced blood transfusions, hospitalization and convalescence.

Mskry T et al ${ }^{5}$ studies comparison of pelvic collections after abdominal, vaginal hysterectomy by sonography. A transvaginal pelvic ultrasound was performed on the second and third post operative day to determine the presence of fluid collection at vaginal vault. Vaginal vault collections were relatively uncommon, often asymptomatic and similar between the two routes of hysterectomy.

Al-Kadri $\mathrm{H} \mathrm{M}$ et $\mathrm{al}^{6}$ reported short and long term complications of abdominal and vaginal hysterectomy for benign disease. A total of 108 women who had hysterectomy were included. The principle indications for vaginal hysterectomy were uterine prolapse and for abdominal hysterectomy, it was uterine fibroids. The overall complication rates were less in vaginal hysterectomy $(23.1 \%)$ as compared to abdominal hysterectomy $(51 \%)$.

Harmanli $\mathrm{OH}$ et $\mathrm{al}^{7}$ reported a comparison of abdominal and vaginal hysterectomy of 288 women. In abdominal hysterectomy the risk of ileus was significantly higher. The need of blood transfusion was similar between the two groups. Vaginal hysterectomy shortened the length of hospitalization significantly.

Garry R el at ${ }^{8}$ reported major medical complications after hysterectomy. Heavy blood loss requiring blood transfusion was $3 \%$ in vaginal hysterectomy and $2.5 \%$ in abdominal hysterectomy. Bowel injury was $1 \%$ in total abdominal hysterectomy and zero in vaginal hysterectomy. Bladder injury was $1 \%$ in both procedures i.e. abdominal and vaginal hysterectomies. Pulmonary embolism was $1 \%$ in total abdominal hysterectomy and zero in vaginal hysterectomy. Over all major complications were $9.5 \%$ in vaginal hysterectomy and $6 \%$ in total abdominal hysterectomy.

Minor complications fever, infection, hematoma (not needing surgery), blood loss (not requiring transfusion) were almost equal in both procedures.

McCracken $G$ et $\mathrm{al}^{9}$ discuses the comparison of laparoscopic assisted vaginal hysterectomy, total abdominal hysterectomy and vaginal hysterectomy. The median total length of stay for total abdominal hysterectomy was 8.3 and 5.9 for vaginal hysterectomy. Major complication hemorrhage and urinary tract damage were almost equal in two groups. In minor complication wound infection, vault and wound hematoma were more in total abdominal hysterectomy. Overall complication rate were 19.8 in total abdominal hysterectomy and 9.3 in vaginal hysterectomy.

\section{WHAT ARE THE OBJECTIVES OF THIS AUDIT?}

To evaluate abdominal versus vaginal hysterectomy in relation to operative and post operative complications.

\section{METHODOLOGY}

This audit report is based on the prospective data of the patients admitted for hysterectomy (abdominal/vaginal) in Obstetrics and Gynaecology Department of Shaikh Zayed Medical Complex, Lahore during the period of $1^{\text {st }}$ November 2005 to $31^{\text {st }}$ October 2006.

The data sample includes all the women having nonmalignant disease and having indication for hysterectomy.

This study includes all women admitted in the Department of Obstetrics and Gynaecology for hysterectomy having a clinical diagnosis confirmed by routine lab ultrasonography/biopsy. 


\section{INCLUSION CRITERIA}

- Benign indications for undergoing hysterectomy

- Written informed consent

- No serious / complicated medical disease

\section{EXCLUSION CRITERIA}

- Inability to undergo an operation due to high surgical or anesthetic risk.

- Malignancy as an indication for the hysterectomy.

\section{INDICATIONS FOR VAGINAL HYSTERECTOMY}

- Patient having utero vaginal prolapse

- High risk patients e.g. (obese, diabetics, HTN)

- $\quad$ Uterine size less than 14 weeks

- Patient preference

\section{PROCEDURE IN WARD}

- Take the patient's and her husbands consent

- Cross match and arrange 2 units of blood

- Bowel preparation and N.P.O a night before the operation

- Patients are given antibiotics at 6:00am before the procedure.

\section{DISCHARGING CRITERIA}

- The patient is afebrile and haemoglobin level are normal and wound is healthy. Haemoglobin level should be above $10 \mathrm{~g} / \mathrm{dl}$.

- In vaginal hysterectomy we ensure that the patient is passing urine without difficulty.

- $\quad$ In abdominal hysterectomy we make sure that there is no abdominal pain.

\section{FOLLOW-UP}

On $8^{\text {th }}$ post operative day for removal of stitches in case of abdominal hysterectomy and vault is visualized for any sign of infection in all the patient.

\section{AFTER SIX WEEKS}

We do examination of abdominal wound / vault. Advise the patient about hormone replacement therapy in case the ovaries have been removed.

Queries of the patient answered.

\section{TECHNIQUE OF ABDOMINAL AND VAGINAL HYSTERECTOMY \\ ABDOMINAL HYSTERECTOMY}

After antiseptic measures, patient is draped. Foley's catheter No. 16 is inserted and the balloon inflated. A pfannensteil incision or midline incision is given according to the size and pathology of the uterus. The skin superficial fasia, deep fasia and peritoneum are incised. The uterus is mobilized and held with the kelly's clamps applied bilaterally over the tubes, ovaries and round ligament. The round ligament is cut and ligated. In case we have to conserve the ovaries, Kelly's clamp is applied medial to the ovaries after making a hole in the broad ligament, it is then cut and ligated. When ovaries are to be removed the infundibulopelvic ligament is clamped, cut and ligated (i.e. lateral to the ovaries), Then the uteriovesical pouch is separated and bladder is pushed down.

The uterine vessel are clamped with Kocker's clamps, cut and ligated. The uteroscral and transverse cervical ligaments are clamped with curved kocker's clamp, cut and ligated. Suture material used for all the pedicles is of vicryle No.1 (Ethicon). The vault is stitched with continuous locking suture using chromic catgut No.1 and is peritonized taking the round and uterosacral ligament so that the vault is suspended. Haemostasis is secured and the peritoneal cavity washed with normal saline. A drain is placed if required in the peritoneal cavity and the abdomen is closed in the reverse order using chromic catgut No. 0 for peritoneum, vicryle No. 1 for rectus sheath and proline or silk for the skin.

\section{VAGINAL HYSTERECTOMY}

The patient is put in lithotomy position and then cleaned and draped. Usually we a part the labia with the help of a silk stitch. Anterior and posterior lips of cervix are held with the valsellum forceps. A circular incision is given around the cervix at the level of insertion of uterosacral 
ligaments. The vaginal skin is then pushed anteriorly, posteriorly and laterally away from the cervix. Posterior and anterior pouch are opened. Firstly the clamps are applied on transverse cervical and part of uterosacral ligament. Which are cut and ligated bilaterally. Then clamps are applied on uterine pedicles and are cut and ligated followed by the tubo-ovarian ligaments with vicryl No.1 (Ethicon). The uterus is removed. Incase we have to remove the ovaries the round ligament is tied separately from the infundibulopelvic ligament. The infundibuloplevic ligament is clamped, cut and ligated lateral to ovaries to secure removal of ovaries. A chromic catgut No. 0 purse string suture is applied by taking a stitch starting from the round ligament all around. The vaginal skin is closed. First of all the anterior and posterior edges of vaginal skin are held with Allis forceps. The lower half of vaginal vault is stitched with interrupted mattress suture and upper half by continues locking suture using catgut No.1. If need be anterior and posterior repair is done and patient is catheterized.

\section{RESULTS}

This audit report is of 200 women who underwent hysterectomy at Gynae/Obs Department of Shaikh Zayed Hospital, Lahore from $1^{\text {st }}$ November 2005 to $31^{\text {st }}$ October 2006. Out of these 200 women 140 were having transabdominal hysterectomies and 60 vaginal hysterectomies.

Table-I shows age wise distribution of woman having hysterectomy.

Vaginal hysterectomy was more $23.3 \%$ in the age group of 40-45 years and trans-abdominal hysterectomy was more in age of $51-55$ years of $35.7 \%$.

Table II described the presenting complaints of women undergoing hysterectomy. In vaginal hysterectomy the most common complaint was heaviness and profusion of uterus $66.6 \%$ and menorrhagia was $33.3 \%$ and there was no case of polymenorrhagia and irregular bleeding in this group. In abdominal hysterectomy menorrhagia was common $48.5 \%$, polymenorrhagia $37.1 \%$ and irregular bleeding, heaviness $7.1 \%$ each.

\begin{tabular}{|l|c|c|c|c|}
\hline \multicolumn{4}{|c|}{ Table-I. Age wise distribution of women having } \\
hysterectomy
\end{tabular}

Table-ll. Presenting complaints

\begin{tabular}{|l|c|c|c|c|}
\hline \multicolumn{1}{|c|}{$\begin{array}{c}\text { Presenting } \\
\text { complaints }\end{array}$} & \multicolumn{2}{c|}{$\begin{array}{c}\text { Vaginal } \\
\text { Hysterectomy } \\
(\mathrm{n}=60)\end{array}$} & \multicolumn{2}{c|}{$\begin{array}{c}\text { Abdominal } \\
\text { Hysterectomy } \\
(\mathrm{n}-140)\end{array}$} \\
\cline { 2 - 5 } & No & $\%$ age & No & $\%$ age \\
\hline $\begin{array}{l}\text { Heaviness \& } \\
\text { Protrusion through } \\
\text { vagina }\end{array}$ & 40 & $66.66 \%$ & 10 & $7.10 \%$ \\
\hline Menorrhagia & 20 & $33.3 \%$ & 68 & $48.5 \%$ \\
\hline Polymenorrhagia & - & - & 52 & $37.1 \%$ \\
\hline Irregular bleeding & - & - & 10 & $7.1 \%$ \\
\hline
\end{tabular}

After clinical evaluation and lab reports decision of hysterectomy was planned which is as shown in table-III In vaginal hysterectomy $66.6 \%$ woman had uterovaginal prolase. $33.3 \%$ dysfunctional uterine bleeding. In abdominal hysterectomy $88.5 \%$ were having fibroids single or multiple while uterovaginal prolapsed and dysfunctional uterine bleeding were only $7.1 \%$ each. 


\section{Table-III. Indication for hysterectomy}

\begin{tabular}{|l|c|c|c|c|}
\hline \multirow{2}{*}{ Indication } & \multicolumn{2}{|c|}{$\begin{array}{c}\text { Vaginal } \\
\text { Hysterectomy } \\
(\mathbf{n = 6 0 )}\end{array}$} & \multicolumn{2}{c|}{$\begin{array}{c}\text { Abdominal } \\
\text { Hysterectomy } \\
\text { (n-140) }\end{array}$} \\
\cline { 2 - 5 } & No & $\%$ age & No & $\%$ age \\
\hline U/V Prolapse & 40 & $66.6 \%$ & 10 & $7.1 \%$ \\
\hline DUB & 20 & $33.3 \%$ & 10 & $7.1 \%$ \\
\hline Fibroid & - & - & 120 & $85.5 \%$ \\
\hline
\end{tabular}

Table IV shows the women undergoing hysterectomy suffering from medical problem. Common are diabetes mellitus and hypertension.

\begin{tabular}{|l|c|c|c|c|}
\hline \multicolumn{4}{|c|}{ Table-IV. Medical Problems } \\
problems & \multicolumn{2}{|c|}{$\begin{array}{c}\text { Vaginal } \\
\text { Hysterectomy } \\
(\mathbf{n = 6 0 )}\end{array}$} & \multicolumn{2}{c|}{$\begin{array}{c}\text { Abdominal } \\
\text { Hysterectomy } \\
(\mathbf{n}-140)\end{array}$} \\
\cline { 2 - 5 } & No & $\%$ age & No & $\%$ age \\
\hline Diabetes mellitus & 8 & $13.3 \&$ & 30 & $21.4 \%$ \\
\hline Hypertension & 10 & $16.6 \%$ & 40 & $28.5 \%$ \\
\hline Anaemia & 6 & $10 \%$ & 8 & $5.7 \%$ \\
\hline HbsAg & - & - & 6 & $4.2 \%$ \\
\hline Anti HCV & - & - & 10 & $7.1 \%$ \\
\hline UTI & - & - & 6 & $4.2 \%$ \\
\hline
\end{tabular}

Table $\mathrm{V}$ described the intra-operative complications of women undergoing hysterectomy. All intra-operative complications described below were in abdominal hysterectomy.

Table VI described the post operative complications of women undergoing hysterectomy in fist 24 hours/ ward stay. These are all minor complications. In vaginal hysterectomy fever is $20 \%$, blood transfusion $16.6 \%$ and urinary retention $10 \%$. In abdominal hysterectomy fever was $42.8 \%$ and blood transfusion $14.2 \%$.

\begin{tabular}{|l|c|c|c|c|}
\hline \multicolumn{3}{|c|}{ Table-V. Intra-operative Complications } \\
\hline Complications & \multicolumn{2}{|c|}{$\begin{array}{c}\text { Vaginal } \\
\text { Hysterectomy } \\
(\mathbf{n}=60)\end{array}$} & \multicolumn{2}{c|}{$\begin{array}{c}\text { Abdominal } \\
\text { Hysterectomy } \\
(\mathrm{n}-140)\end{array}$} \\
\cline { 2 - 5 } & No & $\%$ age & No & $\%$ age \\
\hline Bladder injury & - & - & 2 & $1 \%$ \\
\hline Bowel injury & - & - & 1 & $0.5 \%$ \\
\hline Utreteric injury & - & - & 1 & $0.5 \%$ \\
\hline
\end{tabular}

\begin{tabular}{|c|c|c|c|c|}
\hline \multirow[t]{2}{*}{$\begin{array}{c}\text { Minor } \\
\text { Complications }\end{array}$} & \multicolumn{2}{|c|}{$\begin{array}{l}\text { Vaginal } \\
\text { Hysterectomy } \\
(n=60)\end{array}$} & \multicolumn{2}{|c|}{$\begin{array}{c}\text { Abdominal } \\
\text { Hysterectomy (n- } \\
140)\end{array}$} \\
\hline & No & $\%$ age & No & $\%$ age \\
\hline Fever & 12 & $20 \%$ & 60 & $42.8 \%$ \\
\hline Blood transfusion & 10 & $16.6 \%$ & 20 & $14.2 \%$ \\
\hline Urinary retention & 6 & $10 \%$ & - & - \\
\hline
\end{tabular}

Table VII describes the total hospital stay of women undergoing hysterectomy. In vaginal hysterectomy $53.3 \%$ women stayed for 7 days. Some had more stay due to medical problems. 


\section{Table-VII. Duration of hospital stay}

\begin{tabular}{|l|c|c|c|c|}
\hline \multirow{2}{*}{ No of days } & \multicolumn{2}{|c|}{$\begin{array}{c}\text { Vaginal } \\
\text { Hysterectomy } \\
(\mathbf{n = 6 0 )}\end{array}$} & \multicolumn{2}{c|}{$\begin{array}{c}\text { Abdominal } \\
\text { Hysterectomy } \\
(\mathbf{n - 1 4 0 )}\end{array}$} \\
\cline { 2 - 5 } & No & $\%$ age & No & $\%$ age \\
\hline 4 & 2 & $30.3 \%$ & - & - \\
\hline 5 & 6 & $10 \%$ & 16 & $11.4 \%$ \\
\hline 6 & 4 & $6.6 \%$ & 8 & $5.7 \%$ \\
\hline 7 & 32 & $53.3 \%$ & 40 & $28.5 \%$ \\
\hline 8 & 8 & $13.3 \%$ & 4 & $2.8 \%$ \\
\hline 9 & - & - & 20 & $14.2 \%$ \\
\hline 10 & 2 & $3.3 \%$ & 8 & $5.7 \%$ \\
\hline 11 & 2 & $3.3 \%$ & - & - \\
\hline $12 \&$ more & 4 & $6.6 \%$ & 24 & $17.1 \%$ \\
\hline
\end{tabular}

In abdominal hysterectomy $28.5 \%$ women stayed for 7 days. $14.2 \%$ for 9 days and $17.1 \%$ had stay for more than 12 days. The long stay of 12 or more than 12 days was due to wound infection and management of medical problems like diabetes mellitus and hypertension.

\section{CONCLUSION}

From this audit report we can say that the procedure of hysterectomy either abdominal or vaginal is very safe at Gynae/Obs Department of Shaikh Zayed Hospital, Lahore because of proper sterilization and pre-operative as well as post operative management. There are no major complications or mortality except few minor complications like blood loss, fever, wound infection, constipation, backache which have been managed accordingly and all the patients have been discharged satisfactorily.
This is an audit report of limited data with simple statistic analysis. The bigger audit report with statistical analysis is required to further verifying the result of this audit report.

\section{REFERENCES}

1. Keshavarz $H$, Hillis SD, Kiele BA, Marchbanks PA. Hysterectomy surveillance United States 1994-1999.

2. The Royal College of Obstetricians and Gynecologists. National Evidence based clinical Guide Lines. The management of menorrhagia in secondary care. The Royal College of Obstetrics and Gynaecology 2004. Available for WWW.rcog.org.uk.

3. Bashir R, Parveen Z, Sultana R, Khan B. Two year audit of complications of hysterectomy at Ayub teaching Hospital, Abbottabad. JAMC 2005;17(2):726-29.

4. Dicter RC, Greenspan JR, Strauss LT, Cowart MR, Scally MJ, Peterson HB, DeStefone F, Rbin GL, Ory HW. Complication of abdominal and vaginal hysterectomy among women of reproductive age in United States. The calibration Review o Sterilization. Am J Obstet Gynecol 1982;44(7):841-8.

5. Miskby T, Chatzipapas L, Hart R, Gabrielle A. Nagos A sonographic comparison of pelvic collection after abdominal, vaginal and laparoscopic hysterectomy. Journal of Gynecologic surgery 2001;17(3): 87-90.

6. Al-Kadri HM, Al-Turki HA, Saleh AM, short and long term complication of abdominal and vaginal hysterectomy for benign disease. Saudi Med J 2002;23(7):806-10.

7. Harmanli OH, Gentzler CK Bynn S, Dandoln MH, Grdy T. A comparison of abdominal and vaginal hysterectomy for large uterus. Int J Gynaecol Obstet 2004;87(1):1923

8. Garry R, Fountan J Mason S, Hawe J, Napp V, Abbott J, Clayton R, Phillips G, Whittaker M, Lilford R, Brigman S, Brown Julia. The e VAL $u$ ate study. Two parallel randomized trials one comparing laparoscopic with abdominal hysterectomy, the other comparing laparoscopic and vaginal hysterectomy BMJ 2004:328(7432):129.

9. McCracken G, Hunter D, Morgon D, Price JH. Comparison of laparoscopic assisted vaginal hysterectomy, total abdominal hysterectomy and vaginal hysterectomy. The Ulster Medical Journal 2006; 75 (1) 54-58.

10. M MWRCD Surveillance Sum 2002;51(5505):1-8. 